\title{
A Crise na Psicologia: Análise da Contribuição Histórica e Epistemológica de L. S. Vigotski ${ }^{1}$
}

\author{
Lia da Rocha Lordelo ${ }^{2}$ \\ Universidade Federal da Bahia
}

\begin{abstract}
RESUMO - Este artigo buscou resgatar a importância de L. S. Vigotski como historiador e epistemólogo da Psicologia. Vigotski diagnosticou uma crise e fragmentação na ciência psicológica nos anos de 1920, e destacou no materialismo dialético uma filosofia científica e uma visão de mundo que poderiam realizar a integração metodológica que ele achava necessária à Psicologia, que teria a consciência como objeto principal de estudo. Para isto, são analisados textos de cunho metodológico de Vigotski, em especial "O Significado Histórico da Crise na Psicologia", de 1926. A análise da proposta vigotskiana leva-nos a pensar no sentido da crise e da fragmentação que persiste na própria Psicologia contemporânea, e a refletir mais cuidadosamente sobre a pluralidade metodológica que caracteriza nossa ciência.
\end{abstract}

Palavras-chave: Vigotski, psicologia, epistemologia.

\section{Crisis in Psychology: The Historical and Epistemological Contribution of L. S. Vigotski}

\begin{abstract}
This article aimed to explore L. S. Vigotski's relevance as historian and epistemologist of Psychology. Vigotski diagnosed a crisis and fragmentation in psychological science in the 1920's, and saw in dialectical materialism a scientific philosophy and world vision capable of accomplishing the methodological integration he thought was necessary in Psychology. The main object of study would be consciousness. To accomplish the objective of this study, methodological texts written by Vigotski were analyzed, in particular "The historical meaning of the crisis in Psychology", from 1926. Vigotskian analysis leads us to think about the meaning of the crisis and fragmentation which persist in contemporary Psychology, and invites us to reflect upon the methodological pluralism that characterizes our science.
\end{abstract}

Keywords: Vigotski, Psychology, epistemology.

Este artigo tem como objeto de estudo uma reflexão feita pelo psicólogo L. S. Vigotski, em meados dos anos 20 do século passado. Conhecido nos meios acadêmicos pela elaboração de sua teoria histórico-cultural e por conceitos utilizados na educação, a exemplo da noção de Zona Proximal de Desenvolvimento - ZPD, Vigotski deixou outro legado teórico importante, o qual diz respeito ao estudo da história da psicologia enquanto ciência e à crítica das ideias psicológicas em voga no início do século XX. Este trabalho objetiva mostrar que, a despeito do grande impacto de alguns conceitos Vigotskianos em áreas como a educação e a psicologia do desenvolvimento, o autor possui grande importância como epistemólogo e metodólogo. Isto se revela, no escopo deste artigo, na análise feita por Vigotski da psicologia das primeiras décadas do século XX.

A reflexão aqui apresentada refere-se ao artigo escrito por Vigotski, aproximadamente em 1926, intitulado "O Significado Histórico da Crise na Psicologia: uma investigação metodológica" (Vigotski, 1999a). Nesse artigo, o psicólogo empreende uma análise da crise que, a seu ver, se instalara na Psicologia do início do século XX e propõe as bases de uma nova psicologia científica. Van der Veer e Valsiner (1996)

1 Apoio: CAPES

2 Endereço para correspondência: Rua Plínio Moscoso, 879/903, Apipema. Cep: 40157 215. Fone: (71) 3247 7174. E-mail: lialordelo@ gmail.com afirmam que, no artigo, Vigotski teria se referido, em alguns aspectos, a ideias de filósofos da ciência do século XX, a exemplo de Kuhn, Popper, Lakatos, Hanson e Feyerabend. Os autores ainda localizam neste artigo o caminho preparatório para a concepção da principal teoria de Vigotski, a teoria histórico-cultural.

Em nossa opinião, "O Significado Histórico da Crise na Psicologia: uma investigação metodológica" (Vigotski, 1999a) constitui-se no texto mais representativo de um Vigotski preocupado com os fundamentos da ciência psicológica. O escrito se situa, nas palavras de Rivière (1985), numa posição intermediária entre seus primeiros escritos e os trabalhos em que já formulava mais claramente os primeiros postulados de uma nova teoria da origem social das funções psíquicas superiores. A representatividade deste artigo é evidenciada, para nós, pelo fato de este ser, entre os textos do autor dedicados à análise da psicologia do início do século XX, o de maior densidade teórica, e o que aborda o escopo mais largo de problemas metodológicos e filosóficos. Também diversos autores (Davydov \& Radzikhovskii, 1985; Rivière, 1985; e van der Veer \& Valsiner, 1996), quando buscam uma reflexão teórica sobre as contribuições de Vigotski e não apenas utilizam o seu referencial numa investigação empírica, situam "O Significado Histórico da Crise na Psicologia" como um texto fundamental no conjunto do pensamento Vigotskiano. Assim, do ponto de vista metodológico, este artigo constitui-se num estudo teórico que toma este escrito fundamental como prin- 
cipal objeto de análise. O percurso analítico partirá da crítica da razão psicológica empreendida por Vigotski; dedicar-se-á à presença do materialismo dialético e do marxismo na concepção de método do autor e, então, à proposição feita por ele de uma psicologia de orientação dialética, na qual o conceito de consciência é fundamental.

\section{Crítica da Razão Psicológica ${ }^{3}$}

"O Significado Histórico da Crise na Psicologia" foi terminado, de acordo com Valsiner e van der Veer (1996, pp. 25, 158), no verão de 1926 . Foi uma das épocas em que Vigotski esteve acamado por conta da tuberculose; consta inclusive que foi no hospital que o psicólogo redigiu o texto que, na edição em português, da editora Martins Fontes, tem aproximadamente 200 (duzentas) páginas. O escrito publicado pela editora consta em uma coletânea de textos intitulada Teoria e Método em Psicologia (Vigotski 1999b), sendo "O Significado Histórico..." o maior e talvez o mais importante destes. Este foi um dos escritos de Vigotski que mais demorou para ser publicado oficialmente; embora seja citado por psicólogos soviéticos nos anos 1930, o manuscrito foi perdido durante a II Guerra Mundial, encontrado nos anos 1960 e só veio a ser publicado, finalmente, em 1982, na então União Soviética.

Assim, apesar de tardiamente descoberto, o texto é, de acordo com importantes comentadores de Vigotski (van der Veer \& Valsiner, 1996), uma valiosa forma de nos acercarmos do posicionamento de nosso autor em relação aos problemas filosóficos e epistemológicos que ele considerava relevantes para a psicologia no início do século XX. É curioso saber que podemos delinear estas posições quando conhecemos o conteúdo do artigo: Vigotski procura, em "O Significado...", diagnosticar a crise que se instalara na Psicologia no início do século, e faz isto com o auxílio da história desta ciência.

A crise que Vigotski identifica na ciência psicológica não é exatamente uma novidade, dizem van der Veer e Valsiner (1996), se prestarmos atenção na história da psicologia e atentarmos para os autores que, antes do psicólogo russo, já haviam feito tal diagnóstico. Especificamente um importante autor tratou deste tema em momento muito próximo ao período em que Vigotski elaborou o artigo: o alemão Karl Bühler publicou, em 1927, um livro chamado Die Krise der Psychologie [A Crise da Psicologia]. Já o pensador marxista Georges Politzer morreu antes de concluir seu projeto de crítica das três principais escolas psicológicas e da reconstrução da psicologia, concluindo apenas o volume de crítica da psicanálise (Politzer, 2004). Ainda que o nosso psicólogo não tenha sido exatamente o pioneiro no diagnóstico de uma possível crise na psicologia, Iarochevski e Gurguenidze (1999, p.497), em epílogo à publicação dos textos de caráter metodológico do autor, afirmam, no entanto, que foi Vigotski quem provavelmente contribuiu com a primeira tentativa coerente de explicar a crise da ciência psicológica do ponto de vista do marxismo; eles afirmam que isto é, de fato, uma

3 A expressão "crítica da razão psicológica" é utilizada por Iarochevski e Gurguenidze, no epílogo da compilação de textos de Vigotski Teoria e método em psicologia (1999b). novidade. De qualquer forma, o fato de diagnosticar uma crise na psicologia sugere, minimamente, que Vigotski era um cientista preocupado com as origens e o futuro de sua ciência.

A teoria marxista está na base tanto do diagnóstico que o autor faz da crise quanto da sua proposta de unificar a ciência da psicologia através de uma nova metodologia (marxista, a saber). Ainda falaremos um pouco mais sobre este forte viés marxista; o que é importante, neste momento, é compreender que Vigotski acreditava e defendia, em seu artigo, que o estudo da história da psicologia enquanto ciência demonstraria a necessidade de uma nova psicologia unificadora e uma nova metodologia a ela integrada.

O entendimento de que o estudo da história da ciência estaria amparando uma espécie de diagnóstico metodológico revela-se, em certa medida, logo no início do artigo. Ali Vigotski afirma que pretende empreender uma investigação metodológica baseada no "estudo histórico das formas concretas que a ciência foi adotando e na análise teórica dessas formas para chegar a princípios generalizadores, comprovados e válidos" (1999a, p.210). Ele fala, ainda, em analisar a situação dos sistemas psicológicos da época do ponto de vista da história da ciência, quer dizer, pensando nestes sistemas "como acontecimentos concretos, historicamente vivos" (p.210). A partir de suas palavras, podemos ver que Vigotski de modo algum considerava a história como uma coleção de fatos passados; sua visão de história como algo vivo e em movimento é não apenas muito cara aos pressupostos de sua teoria histórico-cultural, como também declaradamente inspirada em pressupostos marxistas. “(...) não reconhecemos outra história a não ser a marxista" (p. 415), afirma o psicólogo para, em seguida, declarar-se quanto à relação entre psicologia e marxismo: “(...) não podemos dizer: 'psicologia marxista', no sentido em que se diz: psicologia associativa, experimental, empírica, eidética. A psicologia marxista não é uma escola entre outras, mas a única escola verdadeira como ciência: outra psicologia, afora ela, não pode existir" (p.415).

O argumento inicial de Vigotski é o de que não existe ainda uma psicologia geral, unificada. Àquela época existiam, sim, muitas correntes em psicologia; e cada uma delas elegia uma categoria definida como seu objeto de estudo. $\mathrm{O}$ psicólogo toma como exemplos três grandes escolas psicológicas: a psicologia subjetivista tradicional, a reflexologia e a psicanálise. $\mathrm{O}$ fenômeno psíquico, o comportamento e o inconsciente seriam, respectivamente, os objetos de estudo específicos dessas escolas. Em sua opinião, um fato qualquer seria expresso por cada um desses sistemas de forma tão diferente que isso acarretaria, na verdade, em fatos diferentes; certamente isto implicaria também em diferentes métodos de investigação. Desta forma, o acúmulo dos fatos em cada sistema daria origem, com o passar do tempo, a três generalizações e classificações distintas; e gradualmente veríamos nascer três ciências diferentes (pp.213, 214) - um quadro, a nosso ver, de fragmentação da psicologia.

Outros fatores eram, ainda, responsáveis por essa crise, e isso foi apontado não apenas por Vigotski. Outro problema era que a psicologia não parecia se ajustar ao método das ciências naturais. Ao contrário dessas últimas, a psicologia era, ainda, uma "pseudociência", com correntes de pensamento diferentes que não dialogavam entre si, e em que também não era possível aplicar um método de investigação herdeiro, 
em certa medida, do positivismo, tradição importante no início do século XX. A objetividade e a neutralidade eram imprescindíveis em ciência, e a psicologia parecia não lidar com fenômenos que se submetessem a estes critérios de cientificidade. A tradicional dicotomia filosófica entre mente e corpo era grandemente responsável por este problema, para Vigotski.

Neste sentido, a crítica mais severa de Vigotski em relação à ciência e à filosofia da época era justamente a sua "herança" cartesiana - o dualismo de substância que, em sua opinião, fazia a ciência psicológica se fragmentar em correntes teórico-práticas que pouco dialogavam entre $\mathrm{si}^{4}$. Este dualismo era a perspectiva predominante na ciência e na filosofia tradicionais no Ocidente. Nas palavras do próprio autor (Vigotski, 1999a), a psicologia havia sido dividida entre uma corrente dita científico-natural materialista (da qual faziam parte, entre outras correntes, o behaviorismo e a reflexologia), e uma corrente espiritualista (por exemplo, a psicologia descritiva de Dilthey e a psicanálise, que acreditavam na irredutibilidade do fenômeno psíquico). Isto significa que a divisão era, respectivamente, entre uma corrente que negava o psíquico ou subjetivo (de natureza não-material) em favor de uma suposta neutralidade e objetividade, e outra corrente que, por acreditar na existência de uma substância não-material (a subjetividade, o inconsciente ou outro fenômeno psíquico), não se submetia aos parâmetros de uma ciência empírica, que lidasse com fatos reais de forma objetiva e pudesse mensurá-los e controlá-los. Para Vigotski, este era precisamente o quadro da crise na psicologia do início do século XX.

Sabemos que é extremamente complicado julgar um sistema filosófico da magnitude do de René Descartes; o que podemos fazer é, com algum cuidado, lidar com o aspecto de seu pensamento que é mais comentado na filosofia e na ciência ocidentais hoje, visto não ser à toa que nos referimos a um "paradigma" cartesiano. Poderíamos nos arriscar a dizer que a primeira e segunda meditação de Descartes, provenientes das "Meditações sobre a Filosofia Primeira" (Descartes, 1988), instauram alguns dos pilares epistemológicos da modernidade. Descartes argumenta, em suas meditações, em favor da distinção entre corpo e alma e, logo em seguida, acerca da natureza do espírito humano, um "eu”, uma instância interior e privada que conhece a si mesma através da introspecção. A instalação da interioridade é fundamental, epistemologicamente, para conectar a noção de conhecimento à de subjetividade, e o filósofo francês é um dos principais responsáveis por essa ligação. Interessa-nos, aqui, o aspecto de sua doutrina que dicotomizava mente e corpo, atribuindo, a cada uma destas substâncias, naturezas diferentes. Especificamente, no artigo "O Significado Histórico da Crise na Psicologia", Vigotski não responsabiliza Descartes diretamente pelos problemas da psicologia, embora

4 Apesar de Vigotski de alguma forma "responsabilizar" a teoria de Descartes pelos problemas diagnosticados na crise, é quase unânime entre psicólogos que foi a partir do paradigma cartesiano que a constituição do sujeito e, conseqüentemente, do espaço psicológico (Figueiredo, 1996), foi possível. Talvez seja o caso de um feitiço que se vira contra o feiticeiro quando afirmamos que Descartes está na raiz dos problemas de um campo científico que ele mesmo teria ajudado a instaurar. o dualismo mente-corpo fosse um problema que o interessou bastante durante anos (van der Veer \& Valsiner, 1996, p. 157).

Em seguida a este diagnóstico inicial, ainda nas primeiras seções do artigo, Vigotski faz algumas reflexões quanto ao próprio funcionamento da ciência. $\mathrm{O}$ psicólogo acreditava no caráter dinâmico do conhecimento científico, na regularidade da mudança e desenvolvimento das ideias e também no aparecimento e morte dos conceitos (1999a, p.219). Isso é explicado cientificamente se relacionarmos a ciência a alguns fatores (p.219): (1) com o substrato sócio-cultural da época; (2) com as leis e condições gerais do conhecimento científico; (3) com as exigências objetivas que a natureza dos fenômenos que são objetos de estudo coloca ao conhecimento científico no estágio atual da investigação.

Van de Veer e Valsiner (1996, p.160) afirmam que a visão de Vigotski dos determinantes da ciência seria um misto de internalismo e externalismo. Essas duas posturas filosóficas parecem, no mínimo, coexistir, pois de fato Vigotski chama a atenção para a lógica interna da ciência e das condições objetivas que ela nos impõe no processo de investigação, mas também nos lembra de que a ciência é um empreendimento que ocorre no curso da história da sociedade. Entretanto, sabemos que alguns de seus posicionamentos epistemológicos o associam diretamente a alguns filósofos e historiadores da ciência específicos. Em "O Significado Histórico..." (1999a), Vigotski afirmará, um tanto genericamente, que tudo que é descrito como fato já é teoria e que, ao mesmo tempo, por mais abstrato que seja um conceito, ele já encerra, em si, um grau de realidade. Ele procurará, neste contexto, dissolver e reposicionar o que enxergava como falsas antinomias, a exemplo de "conceito versus fato" ou "realidade versus pensamento" (pp. 246-248). Esse tipo de reflexão epistemológica remete ao filósofo da ciência Thomas Kuhn (1987). Kuhn tentou desfazer o que ele pensava ser uma falsa oposição entre as noções de descoberta (novidade de fatos) e invenção (novidade concernente a teorias). Invenção e descoberta não seriam eventos isolados porque a descoberta ou assimilação de um fato novo (no caso, no processo de investigação científica) pressuporia um ajustamento da teoria a este, ou seja, o que temos como fato é algo contingente a leis e condições gerais de conhecimento científico e também a valores históricos e culturais. Certamente, este pequeno ponto de convergência não é suficiente para traçarmos um paralelo significativo entre Vigotski e Kuhn. No entanto, para Iarochevski e Gurguenidze (1999), essa aproximação se veria, principalmente, na própria ideia da natureza das crises na ciência e o caminho para solucioná-las. Vigotski dizia: "A crise é destruidora, mas benéfica: nela se oculta o auge da ciência, seu enriquecimento, sua força, e não a impotência e a falência" (p.324); para depois acrescentar que “(...) a criação da psicologia geral não é uma questão de acordo, mas de ruptura” (p. 336). É sabido que Kuhn, em sua clássica teoria sobre os paradigmas científicos, acreditava que a transição entre um paradigma e outro se daria através de uma "revolução científica", gerada por fenômenos não explicados pelo paradigma vigente - ocasionando uma crise. É o conceito de paradigma e não o de crise que parece ser fundamental para Kuhn, mas não deixa de haver entre ele e Vigotski um ponto de conexão. Angel Rivière (1985, p.34), por sua vez, arrisca uma comparação entre o psicólogo so- 
viético e o filósofo da ciência Paul Feyerabend, quando este se referiu a sistemas científicos "incomensuráveis" - é o que Vigotski diria de escolas como a psicanálise e a reflexologia. É provável, no entanto, que a semelhança termine aí, visto que a "obsessão" de Vigotski pelo método dialogaria muito pouco com o antimetodismo do filósofo austríaco. Em seu famoso Contra o método (Feyerabend ,1989), Feyerabend defenderia justamente que o empreendimento científico seria complexo demais para que fosse guiado por um dado conjunto de regras metodológicas.

Especificamente, Vigotski tentava reposicionar as dicotomias às quais nos referimos no parágrafo anterior defendendo uma relação de natureza dialética entre os termos. Isso nos remete a outra orientação teórico-metodológica fortemente presente em sua obra: o marxismo.

Embora este seja um tópico polêmico nas atuais reflexões sobre a obra Vigotskiana, a maioria dos autores aos quais temos tido acesso (Bakhurst, 1991; Blanck, 2002; Newman e Holzman, 2002; van der Veer \& Valsiner, 1996; Wertsch, 1985) defendem uma forte orientação marxista no psicólogo. No artigo "O significado...", Vigotski já deixa claro que a psicologia geral que ele propõe, em resposta à crise por ele diagnosticada, é uma psicologia dialética ${ }^{5}$, antes de tudo: "A dialética abarca a natureza, o pensamento, a história: é a ciência em geral, universal ao máximo. Essa teoria do marxismo psicológico ou dialética da psicologia é o que eu considero psicologia geral" (p. 393). A ideia era que o método marxista embasasse essa nova ciência psicológica, rompendo com o quadro de fragmentação e crise da época.

\section{Marxismo e Materialismo Dialético}

Temos uma ideia do peso que há em simplesmente pronunciarmos a palavra "marxismo". Este peso existe por muitas razões: pelo que a História enquanto disciplina nos mostrou ao longo do século XX e pelo que nossos próprios olhos e ouvidos têm sistematicamente presenciado em termos de ascensões e declínios, guerras, disputas e impasses ético-políticos de um sem-número de sociedades e de seus específicos modos-de-produção - para utilizar um termo marxista bastante familiar. Outra razão são os muitos sentidos, tendências, contradições e dissidências que são abarcados pelo próprio termo "marxismo", termo que se torna impreciso justamente pela quantidade de significados que guarda. Por isso, é necessário, aqui, distinguir, entre tantos "marxismos", aquele ao qual estamos nos referindo.

Quando falamos da influência ou da relação de Vigotski com o marxismo, falamos, primeiramente, do marxismo tal como interpretado por intelectuais soviéticos entre o fim do século XIX e início do XX. Graham (1993) nos lembra de duas grandes e diferentes interpretações da escola de pensamento fundada por Karl Marx: no ocidente, ela teria sido interpretada genericamente como uma teoria da economia

5 A nomenclatura "psicologia dialética" é utilizada, pelo que vimos, apenas no texto "O Significado Histórico da Crise na Psicologia" (1999a); e pensamos que não era tão fundamental quanto as reflexões metodológicas que Vigotski trazia. Seu objetivo não parecia ser fundar a Psicologia Dialética, mas uma ciência psicológica conformada das preocupações metodológicas trazidas pelo materialismo dialético. e da sociedade; na União Soviética ela teria, no entanto, assumido dois sentidos complementares: o materialismo histórico, que é considerado uma teoria do desenvolvimento social, e o materialismo dialético, que seria, e é o que bem nos interessa, uma filosofia da ciência. Talvez esta classificação de Graham super-simplifique a presença do marxismo no oriente e especialmente no ocidente, onde autores de tradições distintas como Gramsci, Sartre, Benjamin e Lukács, por exemplo, desenvolveram interpretações importantes do marxismo no século XX. No entanto, faz sentido dizer que o materialismo dialético enquanto uma filosofia da ciência é uma das peculiaridades do marxismo russo. O próprio Vigotski, em seu artigo em 1926, já se posicionava quanto a esses problemas: "Não se deve chamar de marxista tudo que se relaciona com o marxismo e, de fato, na maioria dos casos, assim se entende, sem mais explicações" (1999a, p. 412). Ele segue, no mesmo comentário, afirmando ainda que alguns psicólogos tendem, erroneamente, a associar imediatamente o marxismo ao materialismo dialético.

Assim, o marxismo ao qual nos referimos terá, portanto, no materialismo dialético seu ponto de tensão e sua relação estreita com o trabalho metodológico de Vigotski. Aqui não lidaremos com a doutrina materialista dialética posterior à Revolução Russa e ao domínio stalinista em especial, visto que os textos de Vigotski a que fazemos referência datam, em maioria, de até meados dos anos 20. Quando falamos em dialética na tradição marxista, Bhaskar (1996) distingue três sentidos básicos: o método, ilustrando uma dialética epistemológica; uma dialética ontológica, ou seja, um conjunto de leis que governa uma realidade; e uma dialética referente ao movimento da história. Ao longo de nossas reflexões sobre Vigotski, vislumbramos, em alguns momentos, traços desses três sentidos; mas parece que o principal deles é o primeiro, o significado metodológico. Neste sentido, o autor defende, em "O Significado Histórico...", que "o conhecimento da metodologia e história das ciências nos faz ver a ciência como um sistema vivo, em constante evolução ou avanço, de fatos demonstrados, leis, suposições, estruturas e conclusões, que se completam ininterruptamente, são criticados, comprovados, rejeitados parcialmente, interpretados e organizados de novo" (1999a, p.318). Ele arremata, coerentemente, referindo-se a esta como uma compreensão dialética da ciência. Resta-nos, agora, esclarecer melhor o que entendemos por materialismo dialético.

O historiador Loren Graham (1987, pp. 62, 63; 1993, p. 102) sintetiza os preceitos deste que representaria uma filosofia natural para os russos, e transcrevemos ${ }^{6}$ aqui aqueles que se aproximam mais da discussão filosófica direcionada à psicologia Vigotskiana: (1) $\mathrm{O}$ mundo é material; (2) $\mathrm{O}$ mundo material forma um todo interconectado; (3) O conhecimento do homem deriva da realidade natural e social de existência objetiva, e o ser determina a consciência; (4)

6 Transcrevemos aqui os outros preceitos formulados por Graham (1993, p. 102), em livre tradução nossa, para contextualizar melhor a filosofia do materialismo dialético. 1. o mundo é material e feito do que a ciência atual denominaria como matéria-energia. 2. A matéria é infinita em suas propriedades, e portanto o conhecimento humano nunca estará completo. 3. O movimento presente no mundo é explicado por fatores internos, e portanto nenhum agente externo é necessário para realizar este movimento. 
O mundo está em mudança constante; (5) As mudanças na matéria ocorrem de acordo com determinadas leis; (6) As leis do desenvolvimento da matéria ocorrem em diferentes níveis correspondentes a áreas de interesse distintas na ciência; isto significa que é impossível explicar um organismo biológico a partir, por exemplo, de leis físico-químicas; (7) O conhecimento do homem aumenta com o tempo e por conta de sua utilização prática, este "progresso", no entanto, ocorre através da acumulação de verdades relativas e não absolutas.

Esses postulados indicadores do conhecimento do mundo natural formam de modo simplificado, a face do materialismo dialético russo, embora muitos outros autores, afirma Graham (1993), utilizassem estes princípios mesmo no ocidente sem se declararem marxistas ou materialistas dialéticos. Assim, a crescente demanda soviética por uma psicologia de orientação marxista está intimamente relacionada ao pensamento filosófico-científico que acabamos de descrever.

A partir desse pensamento, Vigotski propunha uma espécie de síntese com o intuito de articular um caminho metodológico a ser trilhado pela psicologia, novamente no texto em questão (Vigotski, 1999a).

\section{Marxismo, Vigotski e Método}

Ao afirmar a existência de uma crise na psicologia, Vigotski dizia, ainda, que esse diagnóstico era apenas o início de um caminho metodológico, e era extremamente crítico dos psicólogos que tentavam criar uma psicologia diretamente a partir dos pressupostos filosóficos marxistas.

Um dos argumentos de nosso autor era justamente esse: o de que a psicologia de orientação marxista que eles defendiam não dispunha ainda de sua própria metodologia, e querer encontrar em determinadas obras uma fórmula pronta da psique seria como exigir "a ciência antes da própria ciência" (1999a, p. 358). Vigotski afirmava, sobre marxistas como Plekhanov ${ }^{7}$, por exemplo, que eles "não dispõem, não só de uma metodologia acabada, mas nem mesmo do germe dela: esses autores não tinham se colocado esse problema e suas manifestações sobre o tema têm antes de mais nada um caráter não-psicológico (...)" (p. 359). Vemos, então, que, se a partir dos anos 30, Vigotski foi alvo de críticas por supostamente não se adequar às necessidades do regime soviético. Talvez isto ocorresse justamente por ele se recusar a fazer "ciência antes da própria ciência".

Ao invés disso, Vigotski propunha, a partir de seu diagnóstico da crise, a elaboração de uma psicologia geral. A existência de várias escolas psicológicas dava origem, como dissemos no início, a uma luta não entre tendências dentro de uma mesma ciência, mas entre ciências distintas, que se excluiriam mutuamente. Essas escolas, ao tentarem definir uma psicologia geral, tenderiam a "criar uma só psicologia" (p. 326), ou seja, a unificar a ciência psicológica do ponto de vista exclusivo de seu próprio sistema teórico; e isto definitivamente não era a saída para solucionar a crise. Assim, a psicologia ou metodologia geral surgiria da necessidade de

7 Gueorgui Plekhanov (1856-1918) foi um pensador considerado o "pai" do marxismo russo; foi ele, inclusive, o responsável por cunhar o termo materialismo dialético. dar coerência ao conhecimento científico, e não de escolher um ou outro determinado sistema teórico. Uma primeira chave compreensiva dessa afirmação é que Vigotski deixava claro, em seu artigo, que a análise da crise psicológica tinha um papel fundamental na busca dessa psicologia geral.

O novo modelo de ciência proposto por Vigotski é uma espécie de antecipador da sua principal teoria, a teoria histórico-cultural. De certa forma, é como se a teoria que ele estava gestando fosse a resposta para os problemas que ele enxergava na psicologia. No artigo "Vigotski's Uses of History", Sylvia Scribner (1985) afirma que Vigotski explora novas formas de trazer uma perspectiva histórica para o estudo da natureza humana. Scribner (1985, p. 120) ainda afirma que a análise histórica é a chave do sistema Vigotskiano. Estudar algo historicamente é, argumenta a autora, justamente a essência da abordagem dialética - no caso, a dialética marxista. Ela traz (1985, p.122) uma afirmação fundamental de Vigotski: a de que os processos psicológicos superiores não podem ser explicados pelas leis da natureza nem por leis do espírito (subjetivas, poder-se-ia dizer também), mas que suas raízes devem ser procuradas nas regularidades das leis da história. Quando ele fala "leis da história", estaria se referindo, na verdade, à história materialista de Marx e Engels. Diversos autores que usamos como referências ressaltam o método de Vigotski como o que há de mais marxista em suas contribuições científicas (Newman \& Holzman, 2002; van der Veer \& Valsiner, 1996; Wertsch, 1985).

É também por esta razão que seguimos a esteira desses autores e enfatizamos o papel que Vigotski dava ao método: o sentido de criação da psicologia geral estava na metodologia. Ele enxergava como uma questão de caráter metodológico a possibilidade da psicologia enquanto ciência. Vigotski afirmava, ainda, que a ciência era filosófica até seus últimos elementos e estava perpassada de metodologia. Ele partia do pressuposto de Marx e principalmente Engels (o qual deixou inacabada uma das obras mais representativas da aplicação do marxismo à filosofia da ciência, Dialética da Natureza, Engels 1985) de entendimento da dialética como uma teoria da ciência geral, abarcando a natureza, o pensamento e a história. Dessa forma, o psicólogo russo considerava como psicologia geral precisamente a dialética da psicologia, uma "ciência das formas mais gerais do devir tal como se manifesta no comportamento e nos processos de conhecimento" (1999a, p.247). Certamente, não se tratava de criar uma psicologia que simplesmente respondesse ao marxismo; a questão era bem mais complexa, dizia ele:

(...) a análise da crise e da estrutura da psicologia testemunha indiscutivelmente que nenhum sistema filosófico pode dominar diretamente a psicologia como ciência sem a ajuda da metodologia, ou seja, sem criar uma ciência geral: que a única aplicação legítima do marxismo em psicologia seria a criação de uma psicologia geral cujos conceitos se formulem em dependência direta da dialética geral, porque essa psicologia nada seria além da dialética da psicologia; toda aplicação do marxismo à psicologia por outras vias, ou a partir de outros pressupostos, fora dessa formulação, conduzirá inevitavelmente a construções escolásticas ou verbalistas e a dissolver a dialética em pesquisas e testes; (...) a uma revolução simplesmente terminológica. Em 
resumo, a uma tosca deformação do marxismo e da psicologia. (Vigotski 1999a, p. 392).

Nesta outra declaração fundamental, Vigotski reitera o conteúdo da anterior e termina como uma frase já bastante famosa, citada por diversos teóricos em psicologia:

\begin{abstract}
Mas é preciso saber o que se pode e o que se deve buscar no marxismo. Não se trata de adaptar o indivíduo ao sábado, mas o sábado ao indivíduo; o que precisamos encontrar em nossos autores é uma teoria que ajude a conhecer a psique, mas de modo algum a solução do problema da psique, a fórmula que contenha e resuma a totalidade da verdade científica. (...) O que sim pode ser buscado previamente nos mestres do marxismo não é a solução da questão, e nem mesmo uma hipótese de trabalho (porque estas são obtidas sobre a base da própria ciência), mas o método de construção (...). Não quero receber de lambuja, pescando aqui e ali algumas citações, o que é a psique, o que desejo é aprender na globalidade [grifos do autor] do método de Marx como se constrói a ciência, como enfocar a análise da psique. (Vigotski, 1999a p. 395)
\end{abstract}

Em síntese, era preciso um método, e o materialismo dialético (tal como o circunscrevemos aqui) proveria a metodologia mais integral e adequada à psicologia geral. Embora os livros de psicologia dialética ainda não tivessem sido escritos, era este o caminho de saída para a crise na ciência psicológica.

\section{A Psicologia de Orientação Dialética e a Possibilidade da Consciência}

"Como enfocar a análise da psique" (p. 395): este era um dos desafios fundamentais dentro da psicologia de orientação metodológica marxista para Vigotski. Ele sabia e declarava, inclusive, que o objeto da psicologia - a psique, a consciência - era o mais difícil no mundo e o que menos se deixava estudar (p. 390). Isto ajudava a instaurar o problema que caracterizava a crise: o fenômeno psicológico estava na encruzilhada da batalha entre as duas correntes psicológicas que descrevemos na seção anterior deste artigo, caracterizando a crise na psicologia: se uma tendência recorria a um pólo científico-naturalista e rejeitava a ideia de um fenômeno psíquico irredutível ao físico em termos de propriedades e substâncias, a outra se posicionava no outro oposto do pólo: afirmava a existência de um fenômeno psíquico formado por uma substância própria, e isto dificultava sua sujeição a métodos de apreensão e análise rigorosamente científicos. Em palavras mais simples, o dilema era a existência de uma ciência que negava o subjetivo ou a existência de uma psicologia que, aceitando o fenômeno psíquico, deixava de ser ciência ${ }^{8}$.

8 O já citado livro de Luís Cláudio Figueiredo (1996, p. 22) também localiza este dilema de forma bastante semelhante. $\mathrm{O}$ autor declara que, para instituir a ciência psicológica, a psicologia se vê obrigada, a um só tempo, a reconhecer e desconhecer seu objeto. Se não o reconhece, não se legitima como ciência independente, bem podendo ser anexada a outras ciências, como a medicina, a pedagogia, etc. Se o reconhece, não se legitima enquanto ciência, já que não é capaz de formular leis gerais com caráter preditivo.
Vigotski defende a ideia de uma psicologia objetiva que tem a consciência como objeto primeiro de estudo não apenas em "O Significado Histórico da Crise na Psicologia"; na verdade, esta é uma discussão que se encontra de certa forma "pulverizada" ao longo do artigo, na medida em que é parte do argumento acerca do dualismo na ciência psicológica e da proposição da psicologia de orientação marxista.

Algumas chaves de compreensão do conceito de consciência ${ }^{9}$ para Vigotski são o tipo de substância de que ela seria feita (em mais uma referência ao materialismo dialético) e a ideia de que o desenvolvimento desta consciência seria, de acordo com o filósofo David Bakhurst (1991), entre muitos outros teóricos, constantemente mediada e transformada pelas relações entre a criança e o ambiente social (p. 78). O legado de Vigotski mais difundido no ocidente é, sem dúvida, sua teoria histórico-cultural e alguns conceitos aplicáveis, sobretudo, ao desenvolvimento e educação infantis (o de zona de desenvolvimento proximal, por exemplo); entretanto, alguns dos autores no ocidente que se dedicam a um estudo de caráter teórico da obra Vigotskiana (Bakhurst, 1991, Robbins, 2001; Rivière, 1985; Wertsch, 1985), muitos dos quais estão presentes neste trabalho, colocam como praticamente indiscutível a centralidade do conceito de consciência. Essa afirmação é importante, sobretudo quando oriunda de autores formados na tradição soviética e que desenvolveram seus programas de pesquisa numa espécie de desdobramento do sistema de pensamento Vigotskiano (Davydov \& Radzikhovskii, 1985; Zinchenko, 1985, 1998; Iarochevski \& Gurguenidze, 1999). Para esses autores, Vigotski defenderia que o problema da consciência era um problema real e que, para ser estudado, o conceito deveria ser alçado a um status metodológico diferente, colocado como um objeto de estudo independente (Davydov \& Radzikhovskii, 1985, p. 46). Zinchenko (1985, p. 99) chega a afirmar que a importância da consciência era tanta para Vigotski que este costumava avaliar uma teoria psicológica particular em termos de sua contribuição para o estudo deste fenômeno; para Zinchenko, a consciência sempre foi o maior objeto de estudo na pesquisa do psicólogo.

\section{Considerações Finais}

Uma reflexão importante e que devemos fazer nos dias de hoje é acerca da crise diagnosticada por Vigotski nos anos 20 do século passado. Pensamos que seu "diagnóstico" tinha razão de ser; prova disso é que Vigotski não estava sozinho em seu argumento, tendo seguido o caminho de alguns outros pensadores - da psicologia e fora dela, a exemplo de Georges Politzer (2004) e Karl Buhler (1927). Mas o que é curioso é que esse problema de fragmentação e falta de consenso parece acompanhar a psicologia até hoje. Giorgi, em texto que discute a articulação da psicologia como uma ciência coerente, afirma que a crise não é contemporânea, mas perene (Giorgi, 1985). A crise permanente da psicologia é também um argumento do já citado Luís Cláudio Figueiredo

9 Uma discussão mais aprofundada acerca do conceito de consciência foi feita por nós no artigo "A consciência na obra de L. S. Vigotski: análise do conceito e implicações para a Psicologia e a Educação" (Lordelo \& Tenório, 2010). 
em Matrizes do Pensamento Psicológico (1996); e Thomas Kuhn teria acusado a psicologia de ser uma ciência pré-paradigmática, visto que não possuía um paradigma com o qual a comunidade psicológica científica estivesse de $\operatorname{acordo}^{10}$ (Kuhn, 1987). De fato, em pleno século XXI, não possuímos um paradigma, para usar o termo cunhado por Kuhn, dominante ou consensual.

Entretanto, se a crise é de fato permanente ou perene, algo de bom há de existir nisso. Fourez (2003), ao discutir a crise no ensino de ciências, nos lembra que a palavra crise, no idioma chinês, é escrita com a união de dois ideogramas: um que significa "perigo" e outro que quer dizer "possibilidade" ou "oportunidade". Se a tal integração entre correntes psicológicas planejada por Vigotski (e certamente por muitos outros psicólogos) não se realizou, talvez esta não seja uma prescrição adequada para a psicologia do século XXI. A socióloga da ciência Karin Knorr Cetina (1997) nos alerta de que a ideia de uma unidade metodológica na ciência é uma exigência típica das ciências naturais; uma exigência com a qual, no entanto, nem mesmo essas ciências podem arcar. Esta dificuldade torna duplamente problemática a crença de que as ciências humanas devam se guiar pelos mesmos parâmetros metodológicos que as ciências naturais; primeiro, porque as ciências humanas possuem, sim, necessidades e características singulares; e segundo porque, para Knorr Cetina, dentre as diferentes ciências naturais, há também o que ela chama de diferentes "culturas epistêmicas", ou seja, diferentes estratégias para criar e legitimar conhecimento (1997, p. 260).

Ligada a essa questão, está a importância metodológica da reflexão de Vigotski e a sua intenção de fazer a psicologia integrar-se às ciências naturais (Vigotski, 1999a). Ele cuida, no entanto, de esclarecer que não devemos confundir as ciências naturais com as ciências biológicas, estritamente falando; entra, no conceito de natural, também a natureza social e consciente. Ele propõe, em seguida, que ampliemos o uso do termo natural "a tudo que existe na realidade" (Vigotski 1999a, p. 389). Em outras palavras, a divisão tradicional entre ciências humanas e naturais não faria sentido, pois todo o conhecimento produzido pela ciência pertenceria à natureza.

Como já dissemos aqui, auxiliados pelas afirmações de Knorr Cetina (1997), a integração metodológica que Vigotski propôs talvez já não faça tanto sentido hoje. A crise e a fragmentação epistemológicas que têm caracterizado a psicologia encaminham-na para um quadro não de unificação, mas de pluralidade metodológica, ou de convivência entre diferentes culturas epistêmicas, tais como definidas pela autora (Knorr Cetina, 1997, p. 260).

De todo modo, a pluralidade metodológica a que nos referimos requer cuidado e precisão, em especial no que tange à relação entre a natureza do objeto de estudo e os modos de empreender a análise deste. Se, conforme Rogoff e Chavajay (1995), é preciso antes de tudo formular uma pergunta, o trabalho do pesquisador não termina aí; pelo contrário, está apenas começando. Uma longa história se inicia quando

10 É verdade que as ideias de Kuhn foram sofrendo transformações consideráveis desde a década de sessenta, e a própria ideia de paradigma não é exceção quanto a isso. Os psicólogos estão especialmente desatualizados sobre essas transformações no pensamento de Kuhn. percebemos um fenômeno e nos propomos a investigá-lo. Se o esforço teórico deste trabalho ainda não ilustra bem o caráter dessa reflexão, acreditamos que o olhar de Vigotski sobre o método e sobre a ciência psicológica é um exemplo muito bom disso.

\section{Referências}

Bakhurst, D. (1991). Consciousness and revolution in Soviet philosophy: from the Bolsheviks to Evald Ilyenkov. New York: Cambridge University Press.

Bhaskar, R. (1996). Dialética. In W. Outhwaite \& T. Bottomore (Eds.), Dicionário do pensamento social do século XX. Rio de Janeiro: Jorge Zahar Editor.

Blanck, G. (2002). Vygotsky: o homem e sua causa. In L. C. Moll (Ed.), Vygotsky e a educação: Implicações pedagógicas da psicologia sócio-histórica. Porto Alegre: ArtMed.

Bühler, K. (1927). Die Krise der Psychologie. Jena: Fischer.

Davydov, V. V., \& Radzhikovskii, L. A. (1985). Vygotsky's theory and the activity-oriented approach in psychology. In J. V. Wertsch (Ed.), Culture, communication and cognition: Vygotskyan perspectives. New York: Cambridge UP.

Descartes, R. (1988). Meditações sobre a filosofia primeira. Coimbra: Livraria Medina.

Engels, F. (1985). Dialética da natureza. Rio de Janeiro: Paz e Terra. Feyerabend, P. (1989). Contra o método. Rio de Janeiro: Francisco Alves.

Figueiredo, L. C. M. (1996). Matrizes do pensamento psicológico. Petrópolis, RJ: Vozes.

Fourez, G. (2003). Crise no ensino de ciências? Investigações no Ensino de Ciências, 8(2), 109-123.

Giorgi, A. (1985). Toward the articulation of psychology as a coherent discipline. In S. Koch \& D. Leary (Eds.), A century of psychology as a science (pp. 46-59). New York: McGrawHill Book Company.

Graham, L. (1987). Science, philosophy, and human behavior in the Soviet Union. New York: Cambridge University Press.

Graham, L. (1993). Science in Russia and the Soviet Union: A short history. New York: Cambridge University Press.

Iarochevski, M. F., \& Gurguenidze, G. S. (1999). Epílogo. In L. S. Vygotsky (Ed.), Teoria e método em Psicologia. São Paulo: Martins Fontes.

Knorr Cetina, K. (1997). What scientists do. In T. Ibáñez \& L. Iñíguez (Eds.), Critical social psychology (pp. 261-273). London: SAGE Publications.

Kuhn, T. (1987). A estrutura das revoluções cientificas. São Paulo: Editora Perspectiva.

Lordelo, L. da R., \& Tenório, R. M. (2010). A consciência na obra de L. S. Vygotsky: análise do conceito e implicações para a Psicologia e a Educação. Revista Semestral da Associação Brasileira de Psicologia Escolar e Educacional, 14(1), 79-86.

Newman, F., \& Holzman, L. (2002). Vygotsky: cientista revolucionário. São Paulo: Edições Loyola.

Politzer, G. (2004). Crítica dos fundamentos da Psicologia. A Psicologia e a Psicanálise. São Paulo: UNIMEP.

Rivière, A. (1985). La psicología de Vygotsky. Madrid: Visor.

Robbins, D. (2001). Vygotsky's psychology-philosophy: A metaphor for language theory and learning. New York: Kluwer Academic/Plenum Publishers. 
Rogoff, B., \& Chavajay, P. (1995). What's become of research on the cultural basis of cognitive development? American Psychologist. 50(10), 859-877.

Scribner, S. (1985) Vygotsky's uses of history. In J. V. Wertsch (Ed.), Culture, communication and cognition: Vygotskyan perspectives. New York: Cambridge UP.

Van der Veer, R., \& Valsiner, J. (1996). Vygotsky: uma síntese. São Paulo: Edições Loyola.

Vygotsky, L. S. (1999a). O significado histórico da crise na Psicologia. In Teoria e método em Psicologia. São Paulo: Martins Fontes.

Vygotsky, L. S. (1999b). Teoria e método em Psicologia. São Paulo: Martins Fontes.
Wertsch, J. V. (1985). Vygotsky and the social formation of the mind. Cambridge: Harvard University Press.

Zinchenko, V. P. (1985). Vygotsky's ideas about units for the analysis of mind. In J. V. Wertsch (Ed.), Culture, communication and cognition: Vygotskyan perspectives. New York: Cambridge UP.

Recebido em 16.05.2009

Primeira decisão editorial em 07.01.2011

Versão final em 25.06.2011

Aceito em 13.09.2011

\section{World Congress on Parkinson's Disease and Related Disorders}

14 de Dezembro de 2011

Shanghai, CN 